the land; and by thus misleading Sir John Herschel he has by a coup de plume doubled all our continents.

I. In the first volume of his "Asie Centrale," p. 165, writing on "la hauteur moyenne des continents," Humboldt says, "en cherchant à évaluer l'élévation moyenne de la hauteur des divers continents, c'est à dire la position du centre de gravité du volume des terres élevées audessus du niveau actuel des eaux.

It thus appears that Humboldt used the words "hauteur moyenne," and "hauteur du centre de gravité du volume," as equivalent expressions, which I submit they are not. Had he said "centre de gravité de la surface," he would have been right, for that height is the mean height.

2. But though inaccurate in expression, Humboldt conld never be other than right in principle. Fortunately in the "Asie Centrale" he describes with much detail the process by which he arrives at his so-called "centre de gravite du volume" ; and the process legitimately leads to the mean height. He divides the continent into great areas, which I shall call $a_{1}, a_{2}, a_{3}$ finds the mean height of each $b_{1}, b_{2}, b_{3}, \ldots$. . by taking the mean of several; and then the mean height is

$$
\frac{a_{1} b_{1}+a_{2} b_{2}+a_{3} b_{3} \cdot \text {. . . }}{a_{1}+a_{2}+a_{3} \cdot \text {. }}
$$

A range of mountains he regards as a triangular prism; and to find its mass he multiplies the area of the base by half the mean height, and then computes how much this would raise the whole country if spread over it; and the former number thus increased is, as is plain, the mean height.

3. Arago, in his "Astronomie Populaire," cites the labours of Humboldt with approbation, goes over all the details, adds a vast number more, and deduces numbers approximately the same for the mean height of land. Arago, it is to be observed, invariably uses the phrase " hauteur moyenne." Like Humboldt, he considers that the mean of all the continents lies between 900 and $\mathrm{I}, 000$ feet.

4. Humboldt (Note 360, "Cosmos") apologises for differing from La Place, who, he says, made the mean height of continents more than three times too great. Now La Place's estimate was 3,078 feet.

I conclude, therefore, with the greatest deference, that Humboldt's "centre de gravité du volume" is an inaccurate expression, and that he meant "centre de gravité de la surface," or mean height. If this be so, Sir John Herschel has gbeen led into the error of doubling our continents, which he estimates at a mean elevation of $\mathrm{I}, 800$ feet.

It is a matter of some importance; for Sir Charles Lyell computes that the continent of $\mathrm{N}$. America will be utterly washed away into the ocean by the ordinary processes of degradation in four and a half millions of years. If, indeed, this period is to be doubled, we can take a more cheerful view of the future of that continent. But I greatly fear with Sir Charles that it is limited to four and a half millions of years, unless some upheaval of the land shall protect its short span of existence.

I 13, Eaton Square, March 28

\section{Conscious Mimicry}

THE idea of mimicry in animals being induced through the sense of sight appears to me to deserve more than a passing notice of M. G. Pouchet's statement that changes of colour in prawns, to accommodate them to the colour of surrounding objects, are prevented by removing the eyes of the prawns.

In I869 I expressed my belief that such was the case, and endeavoured to embrace a large class of phenomena, as well as mimicry, within the same instrumentality. I allude to the asserted cases of the human or other foetus being affected through the sense of sight of the mother. But on ascertaining the views of many able medical men, as well as of scientific naturalists, I found opinions so divided on the matter that I did not think it desirable to pursue further inquiries, nor publish my memoranda made at the time. I could not bring myself to see that natural selection alone could produce mimicry. If it were of rare occurrence it would be called a remarkable coincidence, and might reasonably be due to selection, but what is really very general becomes a law, and must be traced to some far more "regular" influence than natural selection.

In basing the idea of mimicry in general upon the supposed act of the foetus being susceptible through the mother's sense of sight, one is aware of the critical nature of the ground adopted, and that possibly nine-tenths of the cases recorded must be put aside as worthless; but I have strong reasoas for believing the one-tenth at least to have been true.

On the other hand, the experiments of Mr. Leslie on the caterpillars of Pontia Rapre, which when enclosed, some in black and others in white boxes, produced chrysalises respectively modified to suit the colour of the box (Sc. Gossip, 1867, p. 261) appear to support my view, as also do those of Mr. Robert Holland (T6. P. 279), in which the cocoon; of the Emperor moth spun in white paper were white, while those on soil or in dead grass were brown.

G. Henslow

\section{The Adamites}

Mr. C. STANiLAND WaKe objects to my remarks on his paper on the "Adamites," which paper he protests is "written at least in a truly scientific spirit." This, I venture to say, is just Mr. Wake's error. He does not seem to be aware that comparative philology has a scientific method, and that words have to be compared by sound and structure according to fixed and even strict principles. Mr. Wake comes upon a Sanscrit word pita, father, and finds in it a primitive root $t a$, which he compares with another syllable $t a$ got by cutting in two in the same way an Arabic verb, 'ata. Had he looked into the structure of Sanscrit, he would have found that pita is the nominative case, and precisely the one that does not show the real crude-form of the word, which is pitar, the tar being a suffix. If it is lawful to compare languages by cutting words up anyhow and finding resemblances among the bits, of course connections may be found between any languages whatsoever. In the same easy way Mr. Wake finds a relation in Polynesian mythology between a divine being called Taata (by the way, he should have taken the name in one of its fuller forms, such as Tannata or Tanoata), and another divine being called Tiki. But these are two different gods with different attributes, why should their names be altered to make them into one?

Mr. Wake thinks it nonsense for me to have set up an imaginary derivation for Paddy and Taffy, as commemorating the same ancestor $A d$ or $T a$, from whom he traces Akkad and Taata. But of all ways of testing methods, one of the most useful is to try whether they can be made to prove transparent nonsense. If they can, it is evident that the method wants correction. As for my communication to you being anonymous, it was so for much the same reason that Mr. Wake's name was not mentioned in it, viz., that it is best to keep the personal element in the background in such matters, and the paper itself is the thing to be judged by. M. A. I.

IF your correspondent, "M. A. I.," instead of endeavouring to negative the conclusions of Mr. Wake's paper "by such nonsense as the reference to Paddy and Taffy," as the author of the paper justly observes, had brought forward the word Adam itself, and shown that, by dividing it into $A d$ and $a m$, and prefix. ing its consonant in each case, we obtain Dad and Mam, father and mother, he might have been held to have been critical, as well as satirical.

I believe, however, that Mr. Wake is wholly wrong in his conclusions, simply because his premisses are wholly wrong.

The word Adam has nothing of the meaning of father in it. The $A d$, which Mr. Wake has so ingeniously made so much of, should for his argument be the Hebrew $A b$, Arabic $A b a$, $a$ father. To suppose that the word Adam has anything of the meaning of father in it shows a complete disregard of its rootmeaning. In Hebrew the verb adam means he reas red or brown, and the substantive Adam means a red or $a$.brown man. The word Edom is from the same root, and means the Red land, probably because Red Sandstone constitutes its principal geological formation, and even adamah, the ground, is so called because of its reddish or dark brozun colour. The Scripture narrative of the origin of man is that the Creator formed "the Adam (or man) of the dust of the adamah (or ground)."

If Mr. Wake's object had been to show that the Adamites were derived from the, earth or earth-born, he would have found little difficulty both by internal and external evidence; he might have instanced the autochthones of the Greeks, the homines (humus, the ground), of the Latins, the yellow-earth men of the Chinese, and the red-clay men of the North American Indians. April 15
B. G. JENKINS 